\title{
The Effect of Confining Pressure and Water Content on Energy Evolution Characteristics of Sandstone under Stepwise Loading and Unloading
}

\author{
Shuren Wang, ${ }^{1}$ Paul Hagan $\left(\mathbb{D},{ }^{2}\right.$ Yanhai Zhao, ${ }^{1}$ Xu Chang, ${ }^{1}$ Ki-Il Song $\mathbb{D}^{,}{ }^{3}$ \\ and Zhengsheng Zou ${ }^{1}$ \\ ${ }^{1}$ Opening Laboratory for Deep Mine Construction, Henan Polytechnic University, Jiaozuo, China \\ ${ }^{2}$ School of Mining Engineering, University of New South Wales, Sydney, NSW 2052, Australia \\ ${ }^{3}$ Department of Civil Engineering, Inha University, Incheon 22212, Republic of Korea \\ Correspondence should be addressed to Ki-Il Song; ksong@inha.ac.kr
}

Received 9 November 2017; Accepted 11 January 2018; Published 19 February 2018

Academic Editor: Rihong Cao

Copyright (C) 2018 Shuren Wang et al. This is an open access article distributed under the Creative Commons Attribution License, which permits unrestricted use, distribution, and reproduction in any medium, provided the original work is properly cited.

To investigate the mechanical properties and energy evolution characteristics of sandstone depending on the water contents and confining pressure, the uniaxial and triaxial tests were conducted. The test results show that the strain energy was stored in the sandstone samples at the prepeak stage, and that is suddenly released when the failure occurred, and energy dissipation is sharply increased at the postpeak stage. The damage and energy dissipation characteristics of the samples are observed clearly under the stepwise loading and unloading process. The critical strain energy and energy dissipation show a clear exponential relationship. The critical elastic energy decreases linearly as the water content increases. As the confining pressure increases, the critical elastic energy of the samples transforms from linear to exponential. The concept of energy enhancement factor is proposed to characterize the strengthening effect induced by the confining pressure on the energy storage capacity of the rock samples. The energy evolution of the sandstone samples is more sensitive to the confining pressure than that of the water content.

\section{Introduction}

In various underground engineering projects such as mining and tunnelling, stability is often governed by groundwater and disturbance during loading and unloading. The surrounding rocks show different responses during the process of loading and unloading, and the water content is also an important factor which can affect on the mechanical behavior of the rock. Therefore, it is significant to study the effect of water content and confining pressure on the damage process and energy evolution characteristics of the rock during stepwise loading and unloading process.

Aiming at the aforementioned problems, lots of experimental researches on the strength, deformation, and failure of different rocks have been carried out. For example, in order to explore the moisture effects on the mechanical properties of rock, Bagde and Petroš [1] conducted tests on dry and saturated samples under dynamic uniaxial cyclic loading; they found that the dynamic fatigue strength and Young's modulus of the saturated samples all reduced obviously. Similarly, the mechanical characteristics of different rock specimens under cyclic loading were studied, and some valuable fruits were obtained [2-6]. For rock mechanics and rock engineering, it is essential to establish the water sensitivity of rock to the strength. It is necessary to assess the potential change of the strength and deformability of the rocks caused by moisture content. Experimental studies were carried out to explain the influence of water content on the strength and elasticity modulus under dry and water saturated conditions [7-13].

In fact, the deformation and failure of rock are forms of energy-driven instability. At present, the research on the energy evolution characteristics during the process of deformation and failure of rock is insufficient. Especially, the influences of the confining pressure on energy input, storage, and dissipation need further studies $[14,15]$. In this paper, 
uniaxial and triaxial compression tests were conducted with sandstone samples depending on the water contents and confining pressure to investigate the mechanical properties and energy evolution characteristics.

\section{Materials and Methods}

2.1. Sandstone Samples. The samples used for this study is Hawkesbury sandstones obtained from Gosford Quarry in Sydney, Australia. According to International Society for Rock Mechanics testing standards, the cylindrical specimens of $46 \mathrm{~mm}$ in diameter are drilled from the block sample and trimmed to be $100 \mathrm{~mm}$ in height. After drying and soaking treatment, tests were conducted for four different water content conditions (i.e., completely dry, 25, 50, and $100 \%$ water content).

2.2. Loading Equipment and Methods. The testing equipment is the MTS-815 rock test system provided by the School of Mining Engineering, University of New South Wales in Australia. The loading was controlled by the vertical force, and the loading rate was set to $0.05 \mathrm{kN} / \mathrm{s}$. All samples were tested according to ISRM standards. The vertical force and the displacement in the process of testing were automatically recorded in real time by the data acquisition system. The compression tests were conducted under the confining pressures, such as $0,2.5,5.0$, and $7.5 \mathrm{MPa}$.

For the stepwise loading test, the load was applied to the samples until it reached the level of $60 \%$ of the uniaxial compressive strength for the beginning. Then, the load is reduced to $10 \%$ of the uniaxial compressive strength. The maximum load for reloading is $12 \%$ higher than the previous load.

\section{Results}

3.1. Uniaxial and Triaxial Compression Tests. As listed in Table 1, the compressive strength of the sandstone samples decreases as the water content increases. And, the compressive strength increases as the confining pressure increases. The results show that the water content causes a significant attenuation effect on the compressive strength and deformation of the samples. The weakening is manifested when the water content of the samples changed from 0 to $25 \%$ : the average attenuation of the peak strength of the samples was $5.04 \mathrm{MPa}$, with an average decline of $11.79 \%$. As shown in Figure 1, as the cycles of loading and unloading increases, the area of each hysteresis loop expands. The result is related to the constant accumulation of fatigue damage and plastic strain which implies energy dissipation becomes gradually significant. The similar observations are reported by Zuo et al. [16]. As the water content increases, the fatigue strength, strain, and slope of the curves decrease significantly, and the plastic loops transform from dense to sparse gradually. The increase of hysteresis loop area shows that the water content would aggravate the energy dissipation. As listed in Table 1, the peak strength and the residual strength increase as the confining pressure increases. When the confining pressure increases from 0 to $2.5 \mathrm{MPa}$, the average growth of the peak strength is $96.91 \%$, and the lowest growth
TABLE 1: Compressive strength depending on the water content and confining pressure.

\begin{tabular}{lcccc}
\hline $\begin{array}{l}\text { Confining pressure } \\
(\mathrm{MPa})\end{array}$ & 0 & 25 & 50 & 100 \\
\hline 0 & 26.32 & 21.04 & 16.67 & 13.96 \\
2.5 & 41.89 & 39.23 & 37.71 & 30.13 \\
5.0 & 54.01 & 48.99 & 45.46 & 40.21 \\
7.5 & 62.84 & 55.64 & 52.10 & 47.69 \\
\hline
\end{tabular}

of the peak strength is obtained from the saturated samples. As the confining pressure increases, the effect of confining pressure on the peak strength becomes indistinct.

3.2. Analysis of Stepwise Loading and Unloading. As shown in Figure 2, the loading curves show linear elastic characteristics and the unloading curves are approximately linear with slightly lower convex. After the first unloading, a relatively large residual strain can be observed between the unloading and loading curves. In the later process of unloading, the residual strain gradually increases, and its increment is almost same in each cycle.

The characteristics of the strain-stress curve can be observed: the plastic strain at the inflection point of the unloading stress is small. The bottom of the closed loop displays a vertical angle, the strain is kept invariable, and the stress rose steeply during the early stage of the reloading. As it is reported by Zuo et al. [16], it is supposed to be the elastic-lagged effect of the rock.

As it is mentioned earlier, a partial recovery of the deformation after a certain period is observed during the unloading process. From the viewpoint of energy, once the unloading behavior is being completed, a small part of elastic energy could not be released. This part of the residual energy would continue to be released and produce resistance, which led to a rapid increase in the elastic modulus when reloading at the next step.

As the cycles of loading and unloading increase, the area of each hysteresis loop expands. The result is related to the constant accumulation of fatigue damage and plastic strain which implies energy dissipation becomes gradually significant. The stress suddenly drops when it reaches the fatigue strength, and a lot of strain energy is released. As the water content increases, the fatigue strength, strain, and slope of the curves decrease significantly, and the plastic loops transform from dense to sparse gradually. The increase of each hysteresis loop area shows that the water content would aggravate the energy dissipation.

\subsection{Energy Evolution Characteristics during Stepwise Loading} and Unloading. The process of rock deformation and failure is accompanied by energy storage and consumption [17]. The external work can be treated as input energy $U$ in rock, and the input energy can be translated into elastic energy $U^{\mathrm{e}}$ and dissipated energy $U^{\mathrm{d}}$, the unit of three energy indexes is $\mathrm{MJ} / \mathrm{m}^{3}$.

As shown in Figure 3, during the stepwise loading and unloading, the input energy $U$ increases in the sandstone samples, and the elastic energy $U^{\mathrm{e}}$ and the dissipated energy 

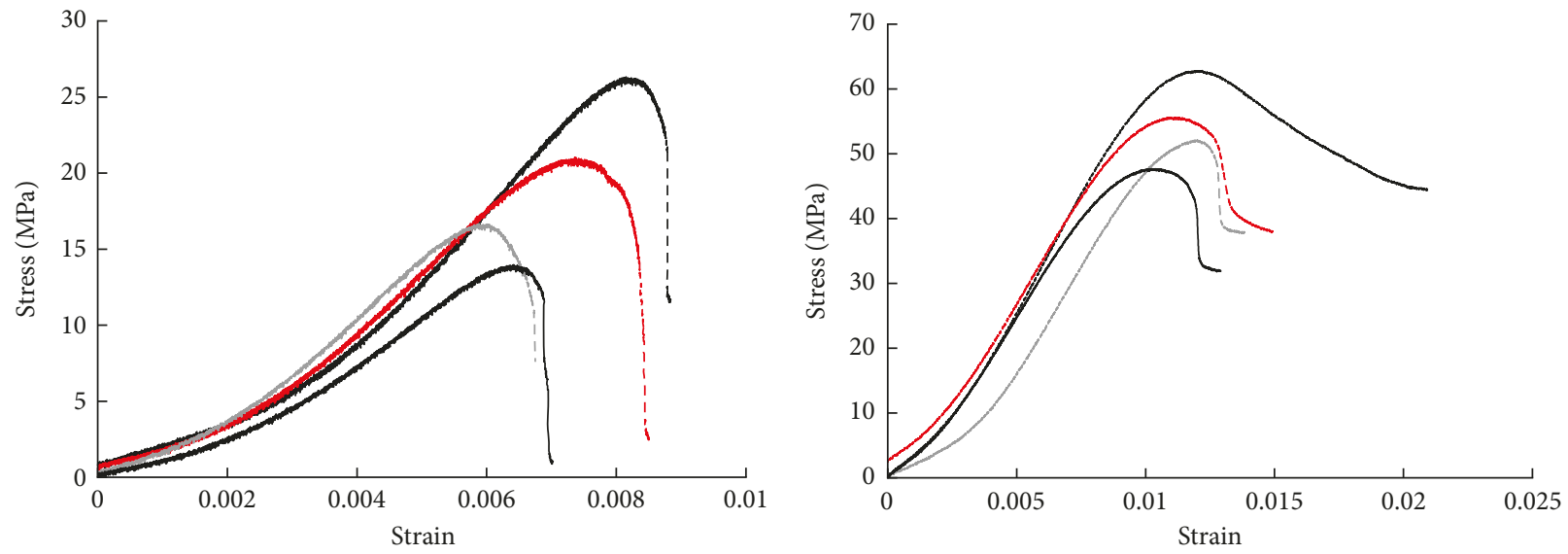

$$
\begin{aligned}
& --0 \% \\
& ---25 \% \\
& ---50 \% \\
& -100 \%
\end{aligned}
$$$$
\text { - - } 0 \%
$$$$
\text { - - } 25 \%
$$$$
\text { -- } 50 \%
$$

(a)

(b)

FiguRE 1: Stress-strain curves of the samples with different water contents. Uniaxial (a) and triaxial (b) compression tests under confining pressure $7.5 \mathrm{MPa}$.

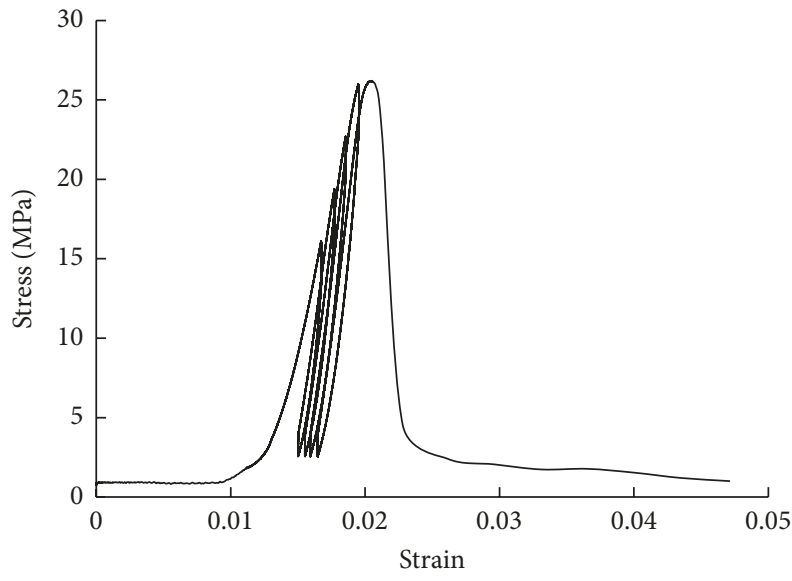

(a)

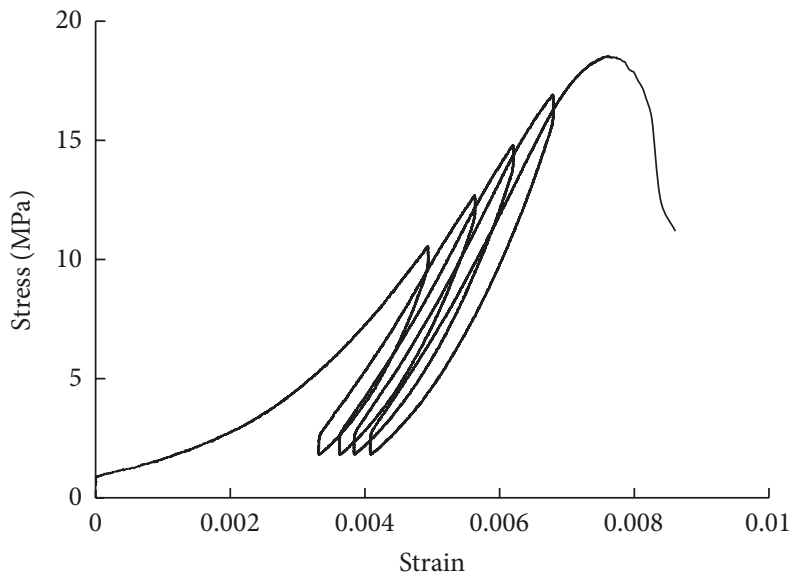

(c)

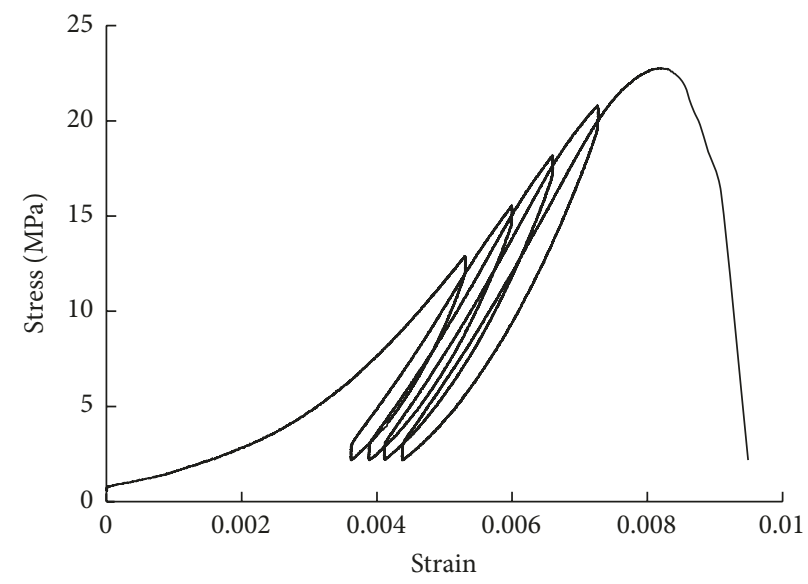

(b)

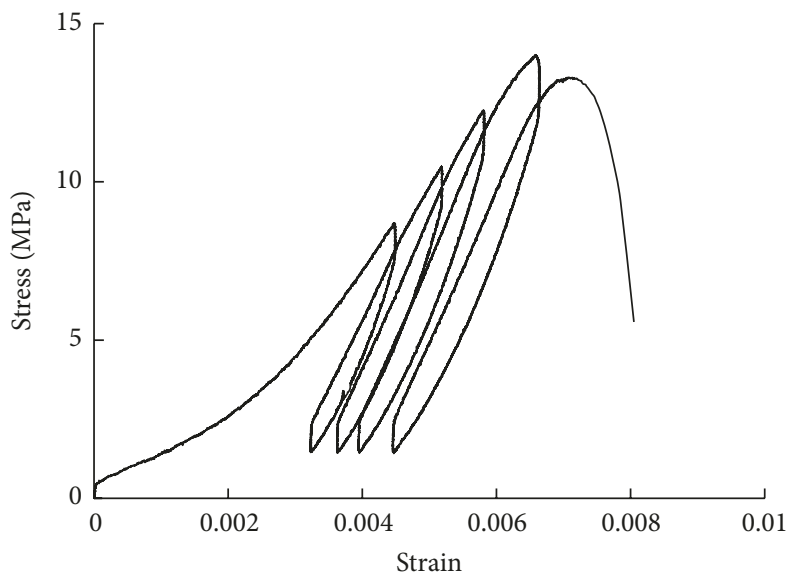

(d)

FIGURE 2: Stress-strain curves of the samples with different water contents under loading and unloading conditions: (a) $0 \%$, (b) $25 \%$, (c) $50 \%$, and (d) $100 \%$. 

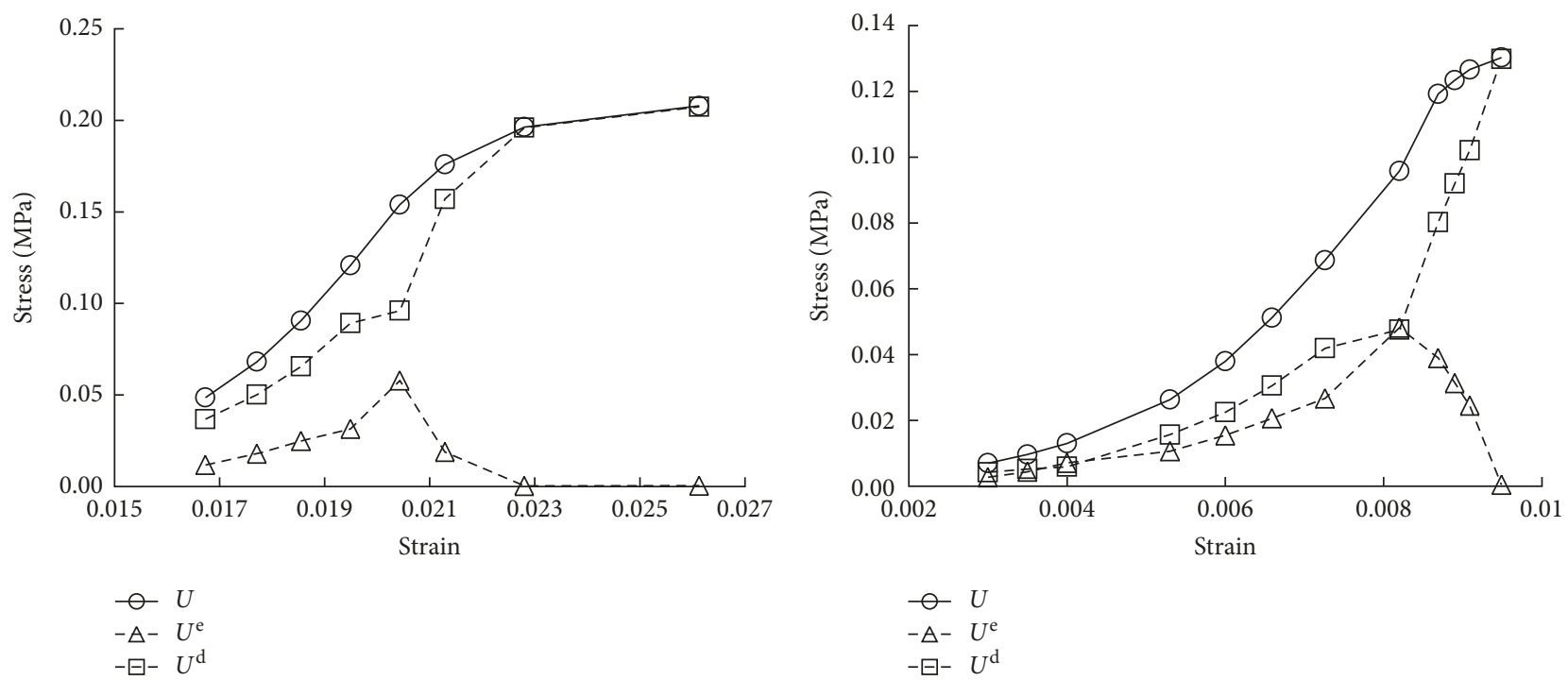

(a)
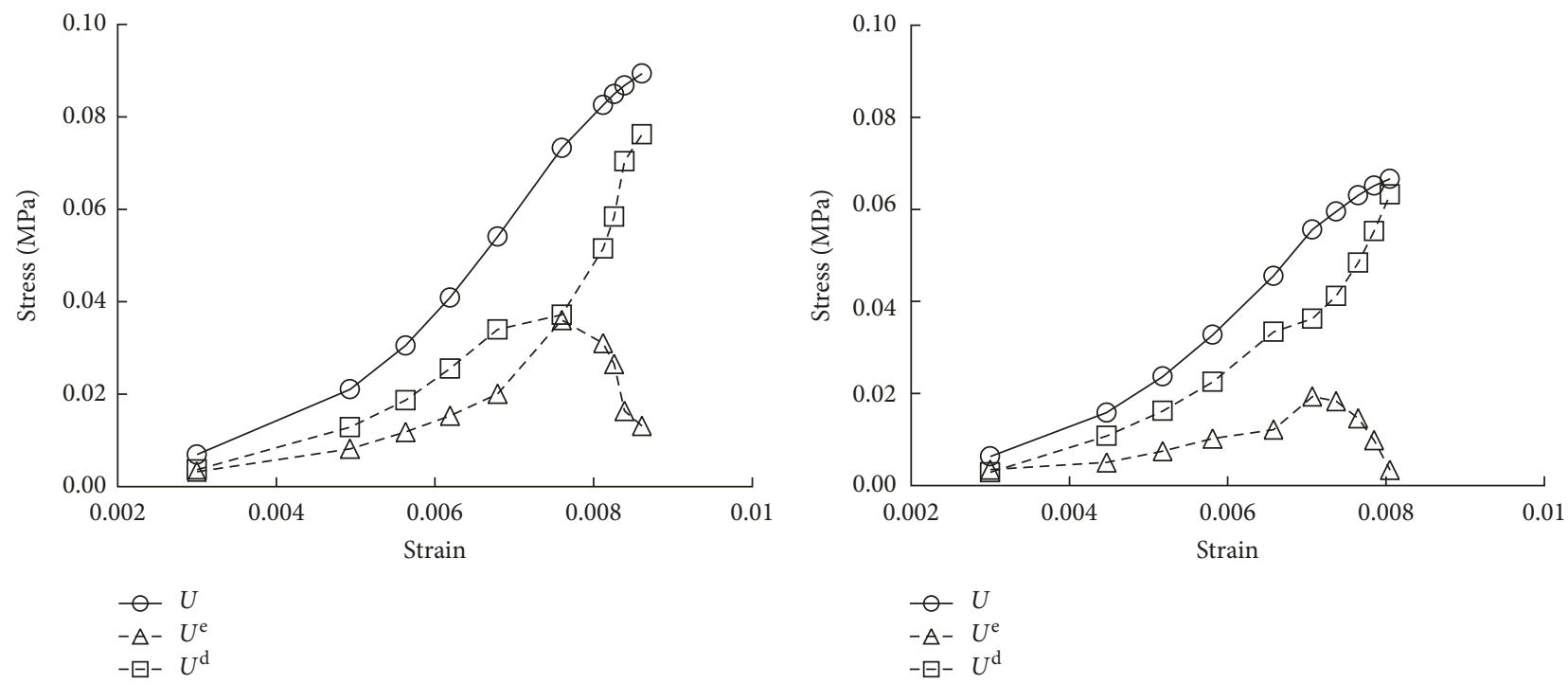

(c)

(d)

Figure 3: Energy evolution curves of samples with different water contents: (a) $0 \%$, (b) 25\%, (c) 50\%, and (d) $100 \%$.

$U^{\mathrm{d}}$ also increase at the prepeak stage. Due to the microfracture damage and large plastic strain of the samples, the dissipated energy $U^{\mathrm{d}}$ is higher than the elastic energy $U^{\mathrm{e}}$. When the stored elastic energy exceeds sandstone's capacity, the stored energy suddenly releases, and the elastic energy curve displays a radical drop, and there is a sharp rise in the energy dissipation curves when the samples failure occurred.

As the water content increases, three energy indexes $U, U^{\mathrm{d}}$, and $U^{\mathrm{e}}$ of the samples vary significantly. The input energies of the sandstone are $0.208,0.130,0.089$, and $0.067 \mathrm{MJ} / \mathrm{m}^{3}$ as the water content increases from $0,25,50$, to $100 \%$.

The water immersion plays a significant role on the energy input behavior. As shown in Figure 4, the critical input energy $U_{p}$ and the dissipated energy $U_{p}^{\mathrm{d}}$ show a clear exponential relationship: as the water content increases, and the critical elastic energy $U_{p}^{\mathrm{e}}$ decreases linearly. The attenuation of the critical energy can be clearly observed: the input energy of the samples decreased by $37 \%$ as the water content varies from 0 to $25 \%$. As the sample approaches to saturation state, the weakening effect of water content on the energy limit becomes less remarkable.

3.4. Effect of Confining Pressure on Energy Evolution. As shown in Figure 5, the greater the confining pressure, the higher the critical elastic energy for the same water content condition. However, for the same confining pressure condition, the greater the water content, the lower the critical elastic energy. It can be found that the confining pressure can strengthen the storage capacity of the elastic energy. The partial elastic energy in the samples cannot be released due to the confining effect in the triaxial compressive strength 


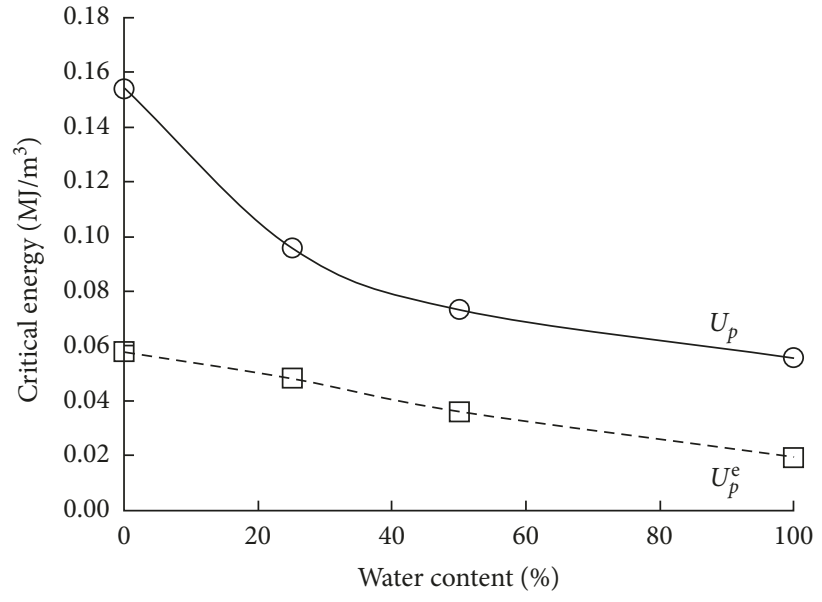

(a)

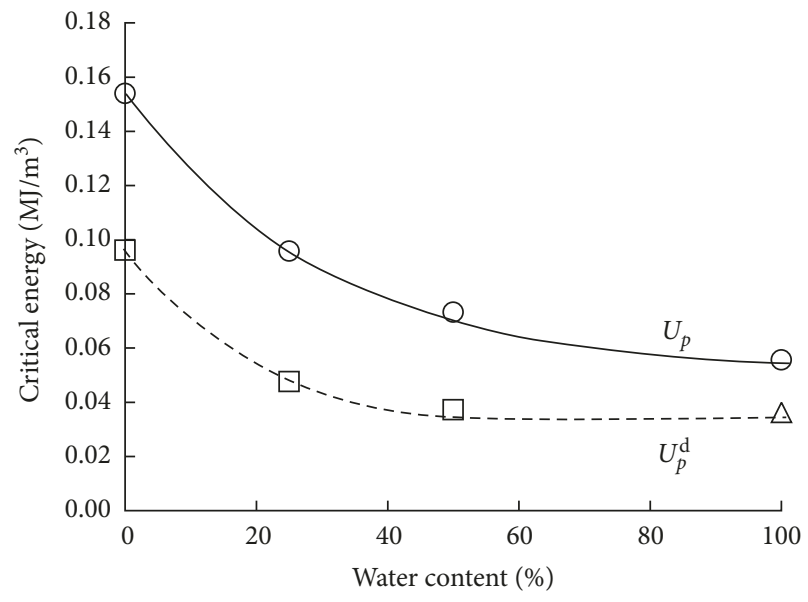

(b)

FIgURE 4: Characteristic curves of the critical energy. (a) $U_{p}$ and $U_{p}^{e}$. (b) $U_{p}$ and $U_{p}^{d}$.

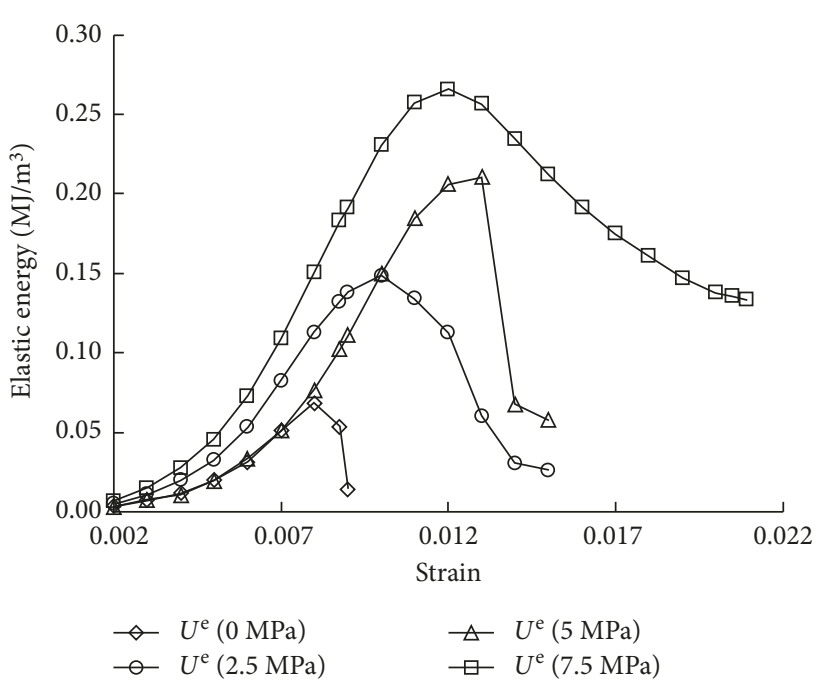

(a)

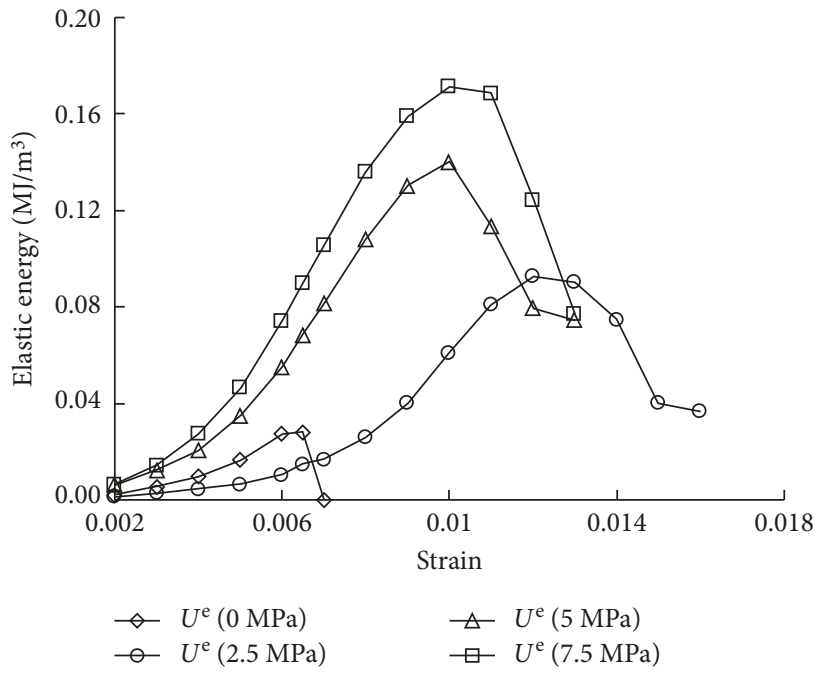

(b)

Figure 5: Energy evolution curves with different water contents: (a) $0 \%$ and (b) $100 \%$.

test. For example, the residual elastic energy of the dry samples increases to $0.0259,0.0578$, and $0.133 \mathrm{MJ} / \mathrm{m}^{3}$ as the confining pressures increases from $2.5,5.0$, to $7.5 \mathrm{MPa}$, respectively. The result demonstrates that the higher the applied confining pressure, the more the remaining residual elastic energy in the samples.

At the postpeak stage, the dissipated energy increases sharply due to the macroscopic crack occurrence, and the samples tend to be unstable. The critical dissipated energy increases as the confining pressure increases. The samples display larger plastic deformation under the higher confining pressure, and the dissipated energy is obviously different from that in the case of the uniaxial condition.

From Figure 6, linear upward trend of $U_{p}^{\mathrm{e}}$ and $U_{p}$ can be observed. As the confining pressure increases, three critical energy indexes improve, but the extent of increment reduces gradually. However, as the water content increases, the energy levels of the samples generally decrease. Three energy indexes of the saturated samples decrease obviously compared to those of the dry samples.

According to the relationship between the critical elastic energy $U_{p}^{\mathrm{e}}$ and the confining pressure $C_{f}$, the enhancement factor $u_{c}$ of the energy storage limit can be defined to describe the strengthening effect of the confining pressure on the energy storage capacity of the samples as follows:

$$
u_{c}=\frac{\Delta U_{p}^{\mathrm{e}}}{\Delta C_{f}} .
$$

When the confining pressure increases from 0 to 2.5 $\mathrm{MPa}$, the enhancement factor $u_{c}$ is higher than that of other pressure conditions. As the confining pressure continuously increases, $u_{c}$ decreases gradually. When the confining pressure increases to a certain degree, it seems 


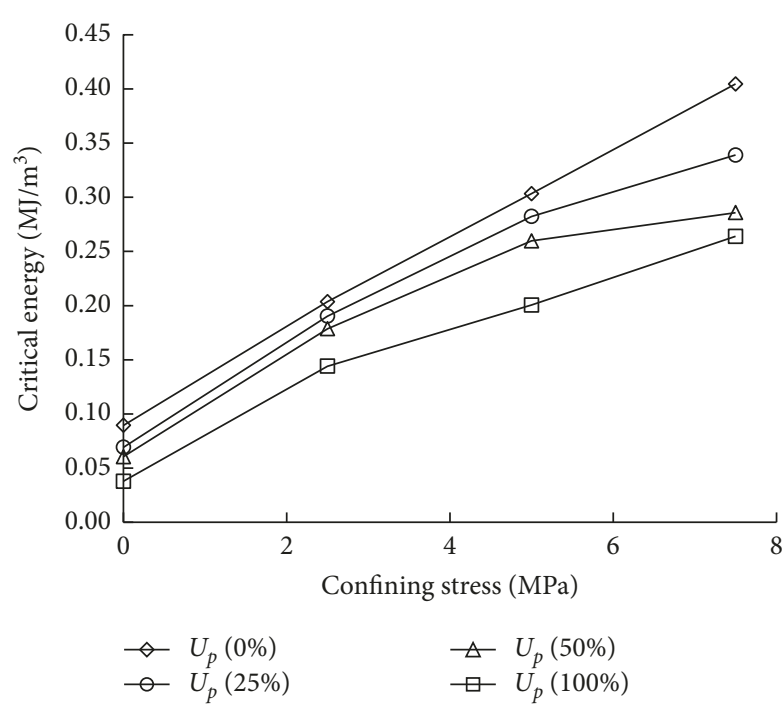

(a)

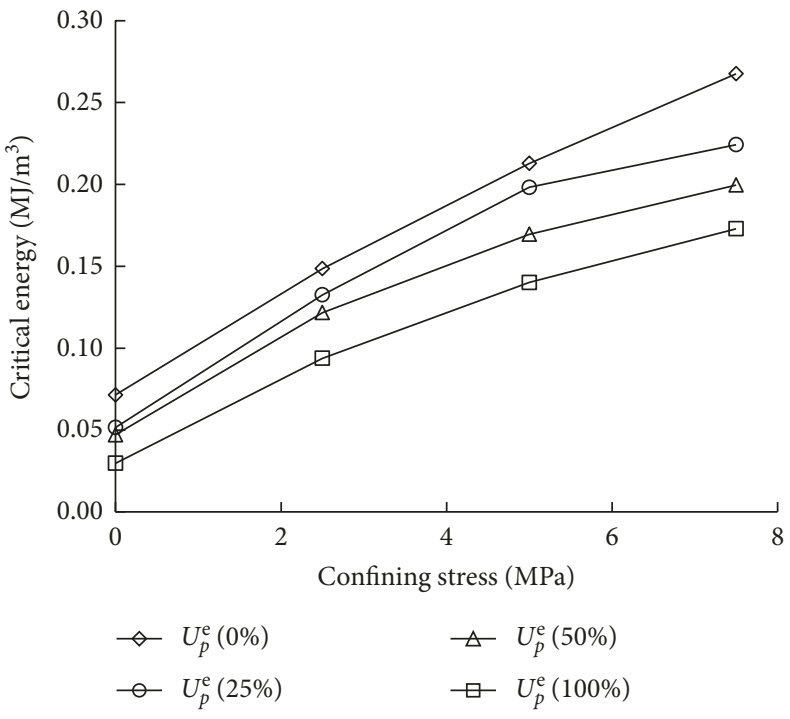

(b)

FIgURE 6: Critical energy curves under different confining pressures: (a) $U_{p}$ and (b) $U_{p}^{e}$.

there is no obvious effect of confining pressure on the energy storage limit. The average value of $u_{c}$ is 0.026 and 0.019 in the dry and saturated samples, respectively. $u_{c}$ of the saturated samples reduces by $26.9 \%$ on average compared to that in the dry state. It can be found that $u_{c}$ decreases as the water content increases.

Based on the test data, the fitting function of the energy storage limit of the sandstone is obtained as follows under coupling action of the confining pressure and the water content:

$$
U_{p}^{\mathrm{e}}=0.0111 C_{f}-0.0644 m_{c}+0.0877 .
$$

In order to compare the influences of the confining pressure and the water content on the energy evolution of the sandstone samples, the limit value of the energy input and storage is used as investigation index $Y$. The limit value of confining pressure and the water content is used as the influencing factor $X$. The sensitivity analysis is performed by using the sensitivity formula as follows:

$$
S=\frac{\Delta X / X}{\Delta Y / Y}
$$

The critical energy index is used as the reference when the confining pressure is $5.0 \mathrm{MPa}$ and the water content is $50 \%$. The value $\sum|S|$ of the confining pressure $C_{f}$ is $1.36 \sim 1.59$, and that value of the water content is less than 1.10. Compared to the water content, the influence of the confining pressure on the input, storage, and dissipation behavior of the energy is more significant.

\section{Discussion}

Based on the test results, it is found that mechanical properties and the energy characteristics of sandstone are governed by the confining pressure and water content. Therefore, it is more practical to study the energy input,

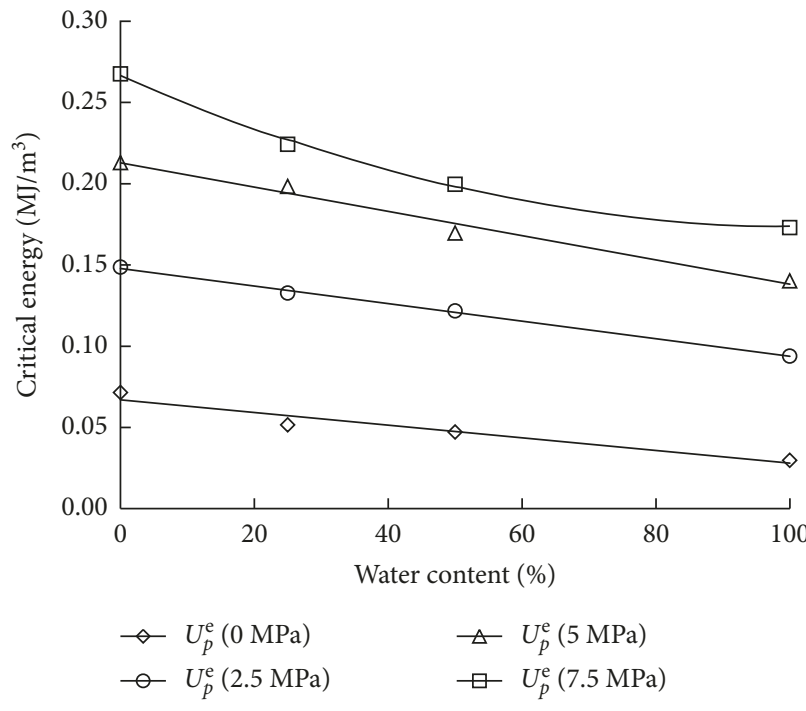

Figure 7: Characteristic curves of critical elastic energy with different water contents.

storage, and dissipation considering the influence of the confining pressure, the water content, and the external loading modes.

The internal damage in the samples can be clearly observed under the stepwise loading and unloading process; the energy dissipation of the damaged samples is obvious, and its energy storage capacity becomes poor. During the uniaxial and triaxial compressive strength tests, the elastic energy is accumulated as long as the stress is smaller than the peak stress. The elastic energy would be stored before the local damage occurred. When the elastic energy exceeds its capacity, sudden failure accompanies a radical release of energy. Sometimes the stored elastic energy would not be completely released. The energy evolution of the samples can 
be described with the input energy $U$, the elastic energy $U^{\mathrm{e}}$, and the dissipated energy $U^{\mathrm{d}}$. Each energy index has a peak value. When the elastic energy exceeds its limit of capacity, it would suddenly release which causes the rock failure. After the rock completely lost the bearing capacity, the input energy and the dissipated energy reach the maximum values. The confining pressure directly affects the overall level and the growth rate of the energy in rock.

The input energy, elastic energy, and dissipated energy increase significantly in the prepeak stage. The growth is accelerated as the confining pressure increases [15]. Although the confining pressure increases to a certain extent, the capacity of the energy storage cannot be improved. In the uniaxial compression strength test, the elastic energy curve drops sharply and the stored energy is completely released within a short time in the postpeak stage. In the triaxial compressive strength test, the confining pressure shows the hindering effect on the release of the elastic energy: the higher the confining pressure, the more the remaining residual elastic energy.

Under the stepwise loading and unloading conditions, the unloading action also induced energy release, but it was different from the energy release in the postpeak stage under uniaxial and triaxial compressive conditions. The released energy caused by unloading action was relatively smaller and would not cause the rock failure, while the elastic energy was stored again in the next loading step. The multistep loading and unloading caused microdamage of the rock samples, and the dissipated energy under stepwise loading and unloading was greater than that under the compressive loading condition. So, the effect of loading mode on energy revolution could be revealed in the three types of experiments.

Compared with the dry samples under the same loading conditions [18], the calculation results of the energy indexes of the partially and fully saturated sandstone samples are relatively lower. The results demonstrate that the effect of water content could not be ignored in the energy evolution of the rock. Moreover, the effect of confining pressure is more obvious than that of the water content. The relationship between the water content and the capacity of rock energy storage is obtained by calculation as shown in Figure 7. The critical elastic energy of the samples decreases linearly when the confining pressure is low, and it decreases exponentially when the confining pressure is high. The critical elastic energy decreases as the water content increases. It can be concluded that the energy release from the wet rock is relatively lower that that from the dry rock under the same stress environment. The water injection can be considered to reduce the stored energy in deep or hard rock engineering with high stress.

\section{Conclusions}

To investigate the mechanical properties and energy evolution characteristics of sandstone depending on the water contents and confining pressure, the uniaxial and triaxial tests were conducted. From the series of test, salient findings are list below.

As the water content increases, the compressive strength and elastic modulus of the sandstone samples decrease, but the compressive strength of the sandstone samples increases as the confining pressure increases.

During the stepwise loading and unloading process, the elastic energy curve is lower than that of the dissipated energy; the energy behavior of the samples mainly displays dissipation. The damage and plastic deformation also govern the energy storage capacity of the samples.

As the confining pressure increases, it significant enhances the input energy, the elastic energy, and the dissipated energy of the samples in the triaxial compressive strength test. However, the water content weakens the input, storage, and growth rate of the strain energy, and it would aggravate the energy dissipation.

The critical indexes of the energy input and storage decrease as the water content increases. The fitting function of the storage limit of the elastic energy is obtained depending on the confining pressure and the water content. However, the effect of the confining pressure on the energy input, storage, and dissipation of the samples is more significant than that of the water content.

\section{Conflicts of Interest}

The authors declare that they have no conflicts of interest.

\section{Acknowledgments}

This work was financially supported by the National Natural Science Foundation of China (51474188, 51774112, and 51310105020), the Natural Science Foundation of Hebei Province of China (E2014203012), 2015 Australian Endeavour Research Fellowship, the International Cooperation Project of Henan Science and Technology Department (162102410027), the International Cooperative Talent Project of Henan Province (2016GH22), the Doctoral Fund of Henan Polytechnic University (B2015-67), and the Taihang Scholars Program. This research was supported by a grant (15SCIP-B105148-01) from the Construction Technology Research Program funded by the Ministry of Land, Infrastructure, and Transport of the Korean government.

\section{References}

[1] M. N. Bagde and V. Petroš, "Fatigue properties of intact sandstone samples subjected to dynamic uniaxial cyclical loading," International Journal of Rock Mechanics and Mining Sciences, vol. 42, no. 2, pp. 237-250, 2005.

[2] K. Fuenkajorn and D. Phueakphum, "Effects of cyclic loading on mechanical properties of Maha Sarakham salt," Engineering Geology, vol. 112, no. 1-4, pp. 43-52, 2010.

[3] M. M. He, N. Li, Y. S. Chen, and C. H. Zhu, "An experimental study of dynamic behaviors of rock under stepwise cyclic loading," Rock and Soil Mechanics, vol. 32, pp. 1287-1296, 2011.

[4] A. A. Araei, H. R. Razeghi, A. Ghalandarzadeh, and S. H. Tabatabaei, "Effects of loading rate and initial stress state on stress-strain behavior of rock fill materials under monotonic and cyclic loading conditions," Scientia Iranica, vol. 19, no. 5, pp. 1220-1235, 2012.

[5] E. L. Liu and S. M. He, "Effects of cyclic dynamic loading on the mechanical properties of intact rock samples under 
confining pressure conditions," Engineering Geology, vol. 125, pp. 81-91, 2012.

[6] Y. B. Fan, O. I. Adewuyi, and C. Feng, "Strength characteristics of soil rock mixture under equal stress and cyclic loading conditions," Geosystem Engineering, vol. 18, no. 1, pp. 73-77, 2015.

[7] B. Vásárhelyi and P. Ván, "Influence of water content on the strength of rock," Engineering Geology, vol. 84, no. 1-2, pp. 70-74, 2006.

[8] X. Hu, B. N. Hong, and Y. M. Meng, "Statistical damage model of red sandstone with effect of water ratio considered," Journal of China University of Mining and Technology, vol. 36, pp. 609-613, 2007.

[9] I. Yilmaz, "Influence of water content on the strength and deformability of gypsum," International Journal of Rock Mechanics and Mining Sciences, vol. 47, no. 2, pp. 342-347, 2010.

[10] Q. L. Yao, X. H. Li, L. H. He, and J. Zhou, "Strength deterioration and acoustic emission characteristics of waterbearing sandstone in uniaxial compressive experiment," Journal of Mining and Safety Engineering, vol. 30, no. 5, pp. 717-722, 2013.

[11] P. L. P. Wasantha, P. G. Ranjith, and D. R. Viete, "Hydromechanical behavior of sandstone with interconnected joints under undrained conditions," Engineering Geology, vol. 207, pp. 66-77, 2016.

[12] S. R. Wang, P. Hagan, Y. C. Li, C. G. Zhang, X. L. Liu, and Z. S. Zou, "Experimental study on deformation and strength characteristics of sandstone with different water contents," Journal of Engineering Science and Technology Review, vol. 10, no. 4, pp. 199-203, 2017.

[13] S. R. Wang, Y. H. Zhao, Z. S. Zou, and H. H. Jia, "Experimental research on energy release characteristics of water-bearing sandstone alongshore wharf," Polish Maritime Research, vol. 24, no. s2, pp. 147-153, 2017.

[14] W. Z. Chen, S. P. Lv, and X. H. Guo, "Research on unloading confining pressure tests and rockburst criterion based on energy theory," Chinese Journal of Mechanical Engineering, vol. 28, pp. 1530-1540, 2009.

[15] Z. Z. Zhang and F. Gao, "Confining pressure effect on rock energy," Chinese Journal of Mechanical Engineering, vol. 34, pp. 1-10, 2015.

[16] J. P. Zuo, H. P. Xie, B. B. Meng, and J. F. Liu, "Experimental research on loading-unloading behavior of coal-rock combination bodies at different stress levels," Rock and Soil Mechanics, vol. 32, pp. 1287-1296, 2011.

[17] H. P. Xie, Y. Ju, L. Y. Peng, and R. D. Peng, "Energy mechanism of deformation and failure of rock masses," Chinese Journal of Mechanical Engineering, vol. 27, pp. 1729-1740, 2008.

[18] G. A. Xu, S. J. Niu, H. W. Jing, S. Q. Yang, and W. L. Wang, "Experimental study of energy features of sandstone under loading and unloading," Rock and Soil Mechanics, vol. 32, pp. 3611-3617, 2011. 


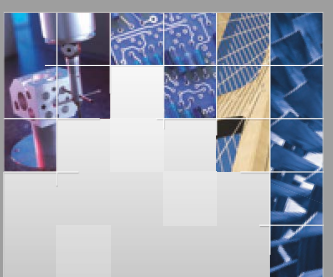

\section{Enfincering}
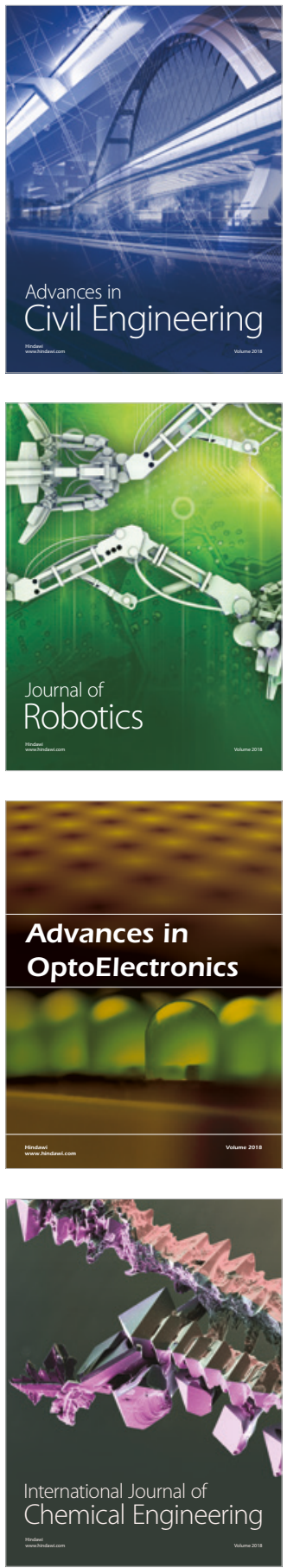

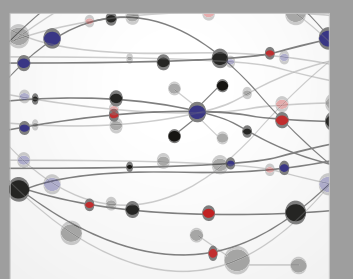

\section{Rotating \\ Machinery}

The Scientific World Journal

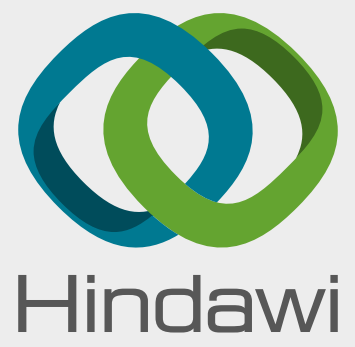

Submit your manuscripts at

www.hindawi.com
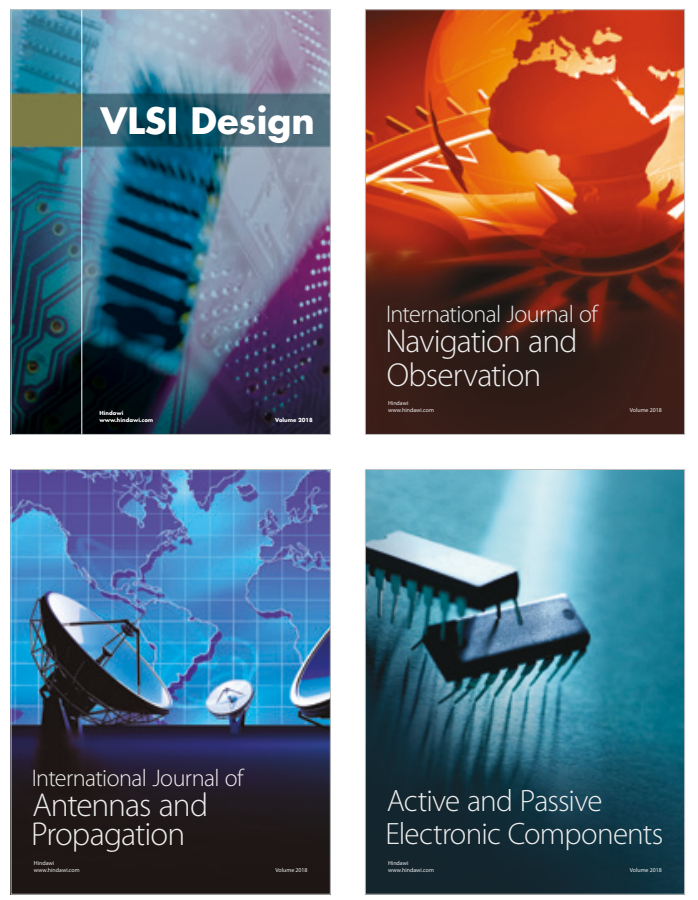
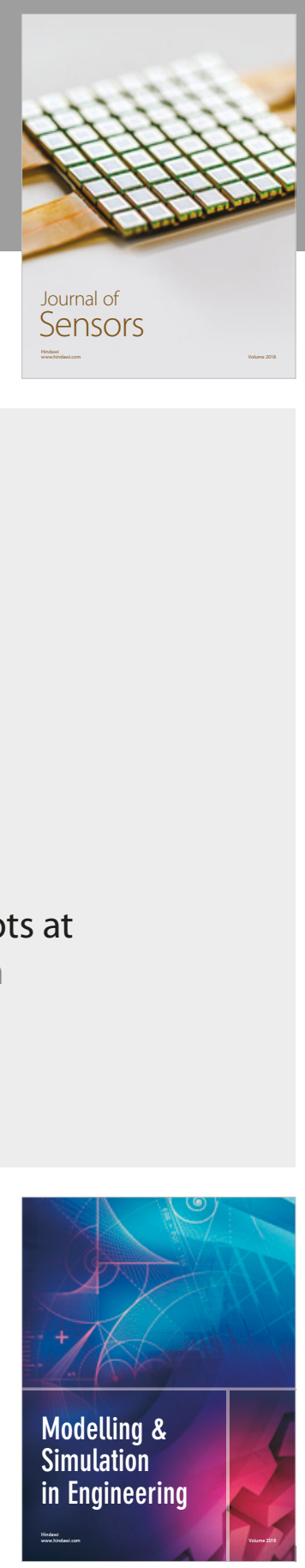

\section{Advances \\ Multimedia}
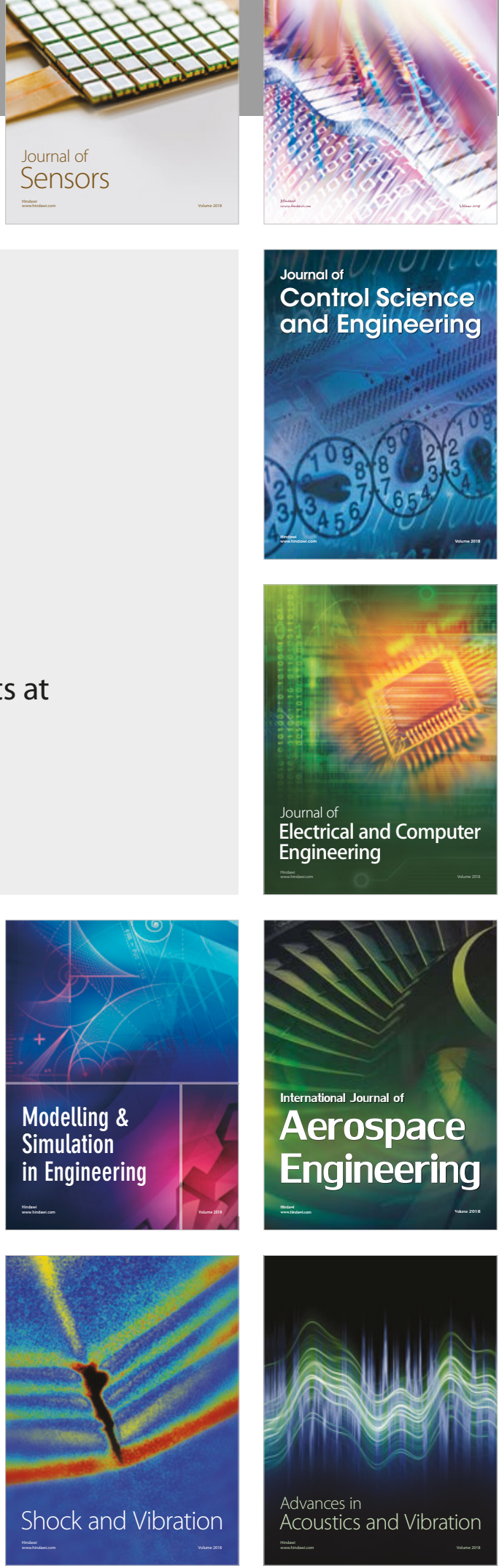